\title{
Invasive reperfusion after 12 hours of the symptom onset remains beneficial in patients with ST-segment elevation myocardial infarction: Evidence from a meta-analysis of published data
}

\author{
Hai-Tao Yang ${ }^{1}$, Wen-Juan Xiu ${ }^{1}$, Ying-Ying Zheng, Fen Liu ${ }^{2}$, Ying Gao ${ }^{3}$, \\ Xiang $\mathrm{Ma}^{1}$, Yi-Ning Yang ${ }^{1}$, Xiao-Mei $\mathrm{Li}^{1}$, Yi-Tong $\mathrm{Ma}^{1}$, Xiang Xie ${ }^{1}$
}

${ }^{1}$ Heart Center, First Affiliated Hospital of Xinjiang Medical University, Urumqi, Xinjiang, China

${ }^{2}$ Laboratory of Coronary Heart Disease, Xinjiang Key Laboratory of Cardiovascular

Diseases Research, Urumqi, Xinjiang, China

${ }^{3}$ Department of Cadre Ward, First Affiliated Hospital of Xinjiang Medical University, Urumqi, Xinjiang, China

\begin{abstract}
Background: Early myocardial reperfusion therapy $(<12 \mathrm{~h})$ in patients with acute myocardial infarction (AMI) can significantly improve their prognosis. However, the effect of late reperfusion ( $>12 \mathrm{~h}$ ) remains controversial. In this study, the effects of late reperfusion versus standard drug therapy on the outcomes of patients with AMI were evaluated by systematic review and meta-analysis.

Methods: PubMed, Embase, Medline, Cochrane, Wanfang, and CNKI databases were searched for eligible studies for the present study. Meta-analysis was performed using RevMan 5.3.3 software. Relative risk (RR) and the $95 \%$ confidence interval (CI) were used to compare the outcomes between the two groups. The main outcome measures were major adverse cardiac events (MACEs), all-cause mortality, recurrent myocardial infarction (MI), and heart failure.

Results: Eighteen studies were identified including 14,677 patients, of whom 5157 received late reperfusion with percutaneous coronary intervention (PCI) and 9520 received medication therapy (MT). Compared to MT, late PCI was associated with decreased all-cause mortality (RR 0.60, $95 \%$ CI 0.44-0.83; $p=0.002$ ), MACEs (RR 0.67; 95\% CI 0.50-0.89; $p<0.001$ ), and heart failure (RR 0.76; 95\% CI 0.60-0.97; $p=0.03)$, while there was also a trend toward decreased recurrent MI (RR 0.70; 95\% CI 0.47-1.05; $p=0.08$ ). However, subgroup analysis according to time to PCI showed that the clinical benefit was only from PCI after $12 \mathrm{~h}$ but not from 2 to 60 days of the onset of symptoms.

Conclusions: The present meta-analysis suggested that PCI performed $>12$ h but not 2-60 days after AMI is associated with significant improvement in clinical outcomes. However, these results need further rigorously designed large sample size clinical trials to be validated. (Cardiol J 2019; 26, 4: 333-342)
\end{abstract}

Key words: late reperfusion, percutaneous coronary intervention, clinical outcome, acute myocardial infarction, meta-analysis

\section{Introduction}

Acute myocardial infarction (AMI) is one of the leading causes of death worldwide [1]. Early myocardial reperfusion has become a primary therapeutic goal of ST-segment elevation myocardial infarction (STEMI) [2]. A large number of clinical practices have confirmed that the opening

Address for correspondence: Xiang Xie, MD, PhD, FACC, Heart Center, First Affiliated Hospital of Xinjiang Medical University, No. 137, Liyushan Road, Urumqi, 830011, China, tel: +86-991-4365381, fax: +86-991-4366169, e-mail: xiangxie999@sina.com

Received: 30.09.2017 Accepted: 6.03.2018 
of an infarct related artery (IRA) within $12 \mathrm{~h}$ after onset significantly improved the prognosis of AMI patients [3-5]. However, there are two views on the treatment of patients over the reperfusion time window ( $>12 \mathrm{~h}$ ) in clinical practices. One is the standard drug treatment, including the double anti-platelet, $\beta$-blockers and statins, while another is the late reperfusion by percutaneous coronary intervention (PCI). However, the benefit of late $\mathrm{PCI}(>12 \mathrm{~h}$ ) has been controversial. Recent studies [6-8] have shown that late PCI may improve the cardiac function and clinical outcomes of AMI patients compared to medication therapy (MT). However, several studies reported conflicting results [9-11]. Abbate et al. [7] performed a metaanalysis including 10 randomized controlled trials (RCTs) indicating that PCI of the IRA performed late (from $12 \mathrm{~h}$ to 60 days) after AMI is associated with significant improvements in cardiac function and survival. However, this published meta-analysis included patients who received late PCI within $12 \mathrm{~h}-60$ days. That is, patients who received PCI with $12-48 \mathrm{~h}$ of the onset of symptoms were included. In fact, the clinical outcomes may differ between individuals receiving PCI within $12-48 \mathrm{~h}$ and those receiving PCI within 2-60 days [9, 12]. Hochman et al. [9] reported that late PCI within 3-28 days (median 8 days) after AMI did not show clinical benefit. However, Gierlotka et al. [12] found late reperfusion within $12-48 \mathrm{~h}$ reduced the 12 -month mortality rate compared to medication therapy alone in AMI patients. Therefore, although Abbate et al.'s [7] meta-analysis demonstrated that late PCI (from $12 \mathrm{~h}$ to 60 days) after AMI is associated with significant improvements in cardiac function and survival, the best cut-off of time window for late PCI remains uncertain.

The aim of this study was to perform an updated systematic review and meta-analysis of all eligible studies to further clarify the effect of late PCI versus MT on the prognosis of AMI patients and the best cut-off time window for late PCI.

\section{Methods}

\footnotetext{
Retrieval strategy

Eligible studies published in PubMed, Embase, Medline, Cochrane, Wanfang, and CNKI databases were searched from 1980 to November 2016 using the following keywords: "acute myocardial infarction (AMI)"; "percutaneous coronary intervention (PCI)"; "reperfusion"; "subacute myocardial infarction"; "acute coronary syndrome"; and "medication therapy".
}

The main outcome measures were major adverse cardiac events (MACEs), all-cause mortality, recurrent myocardial infarction, and heart failure (HF). Eligible studies published in both Chinese and English were included in the present study.

\section{Inclusion and exclusion criteria}

Randomized controlled trials were included, as well as observational studies and cohort studies in which: 1) enrolled patients with AMI received treatments of late reperfusion $(>12 \mathrm{~h}$ ) or MT; 2) compared outcomes between treatments of MT and later reperfusion; and 3) reported clinical outcomes, such as all-cause mortality, MACEs, HF, and other outcomes.

Excluded were: 1) studies assessing the role of early reperfusion; 2 ) studies that only reported one therapy strategy; and 3) studies not involving human subjects.

\section{Study selection}

The procedure of eligible study selection is shown in Figure 1. Initially 1623 studies were searched. Of these, $1602(98.7 \%)$ were excluded by title and abstract search because of irrelevant content, non-English and non-Chinese articles, animal subjects, outcomes of interest not reported, or other reasons. The remaining 21 studies were full-text reviewed, and 4 studies were excluded due to event rates not reported and outcomes of interest not reported. Finally, 18 studies [8-25] met the inclusion criteria and were included in the meta-analysis.

\section{Data extraction}

Two investigators (H.T.Y. and X.X.) carried out the data extraction using standardized data extraction forms. Discrepancies were resolved by consensus. The following information was collected from each study: name of the first author, year of publication, ethnicity or geographic location of the study subjects, study design, procedural and management strategy, ages, gender, and relevant outcomes.

\section{Outcomes}

The primary outcomes for this systematic review were MACEs and all-cause mortality. Secondary outcomes were recurrent $\mathrm{MI}$ and $\mathrm{HF}$.

\section{Methodological quality}

The recommendations of the Meta-analysis Of Observational Studies in Epidemiology (MOOSE) Group were followed to perform this meta-analysis, 


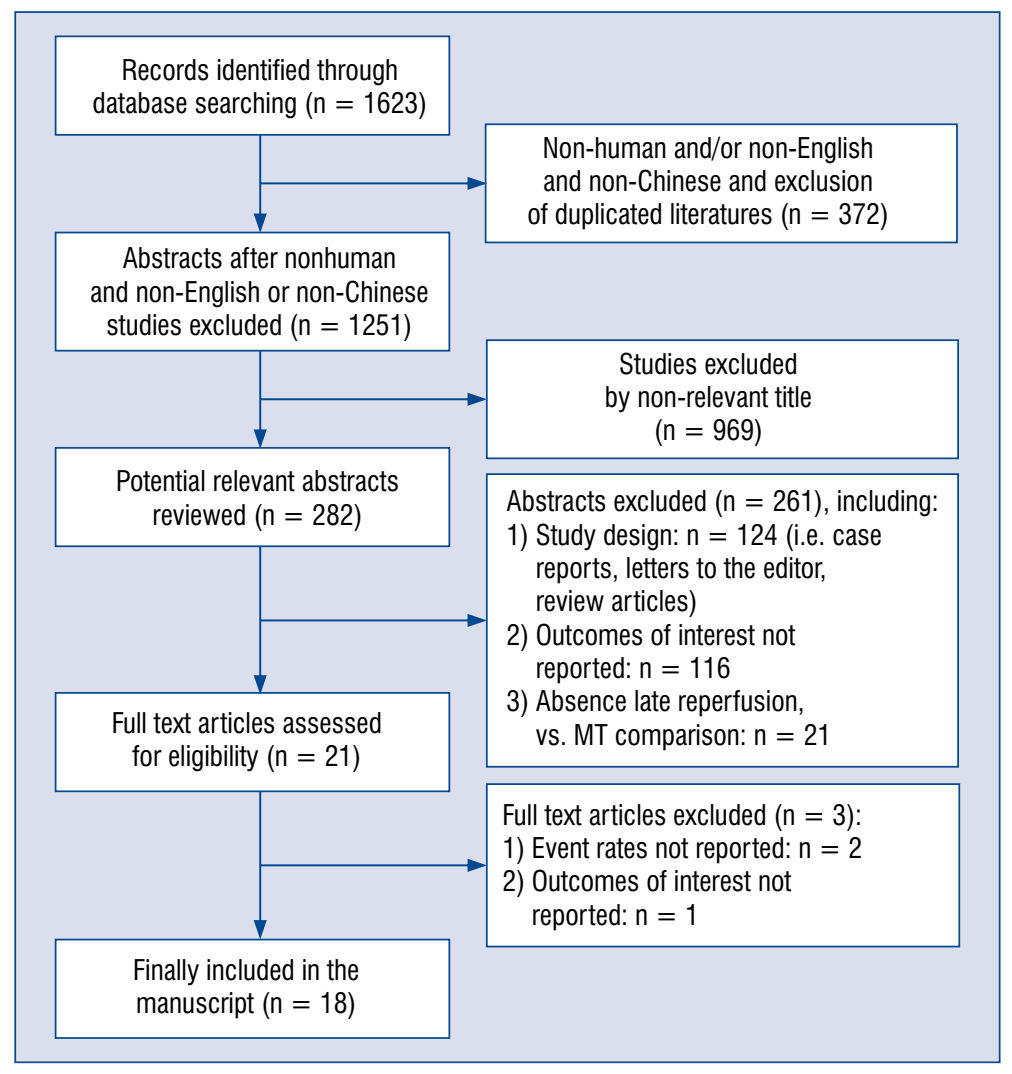

Figure 1. Flow chart of identification of eligible studies; MT — medication therapy.

including study selection, data collection, analysis, and reporting of the results.

Weighted risk ratios (RRs) were calculated and $95 \%$ confidence intervals (CIs) for categorical variables and mean difference, and $95 \% \mathrm{CI}$ for continuous variables. Heterogeneity testing was performed using the Cochrane Q-statistic and $\mathrm{I}^{2}$-statistic. Pooled effect sizes were determined using a fixed-effects model (the Mantel-Haenszel method) when heterogeneity was negligible $\left(\mathrm{I}^{2}<50 \%\right)$ or a random-effects model (the DerSimonian and Kacker method) when significant heterogeneity was present $\left(\mathrm{I}^{2} \geq 50 \%\right)$. Sensitivity analysis was also performed to evaluate the effect of each study on the combined RRs by omitting each study in turn. Publication bias was visually estimated by assessing funnel plots. All analyses were performed using RevMan 5.3.3 software (Cochrane Collaboration, The Nordic Cochrane Centre, Copenhagen) as described previously.

\section{Results}

\section{Study and patient characteristics}

Table 1 listed the characteristics of the 18 studies [8-25] that met eligibility criteria. Of these, 4 are observational studies $[12.14,22,23]$ and
14 are RCTs [8-11, 13, 15-21, 24, 25]. The present analysis includes 14,677 patients, of whom 5157 received late myocardial reperfusion and 9520 received MT. The mean age of study participants was 58.4 years. Mean follow-up time was 12 months.

\section{MACEs}

Thirteen of 18 studies [8, 9, 11-18, 21, 23, 24] reported 1067 MACEs during follow-up. There was significant heterogeneity among included studies $\left(\mathrm{I}^{2}=81 \%, \mathrm{p}<0.001\right)$; therefore, the random-effects model were used to calculate the $R R$ value. In all patients, the meta-analysis results suggested that late PCI was associated with a lower incidence of MACEs (RR 0.67; 95\% CI 0.50-0.89; $\mathrm{p}<0.001$, Fig. 2A) than MT. When stratified analysis according to time to PCI was performed, the heterogeneity disappeared in the $>12 \mathrm{~h}$ arm $\left(\mathrm{I}^{2}=0 \%\right)$ and weakened in the 2-60 days arm $\left(\mathrm{I}^{2}=79 \%\right)$. Subgroup analysis showed that a decreased MACE rate was observed only in the $>12 \mathrm{~h}$ arm but not in the 2-60 days arm (Table 2 ).

\section{All-cause mortality}

Fourteen of 18 studies [8, 9, 11-17, 20, 21, 23-25] reported an outcome of all-cause mortality. 


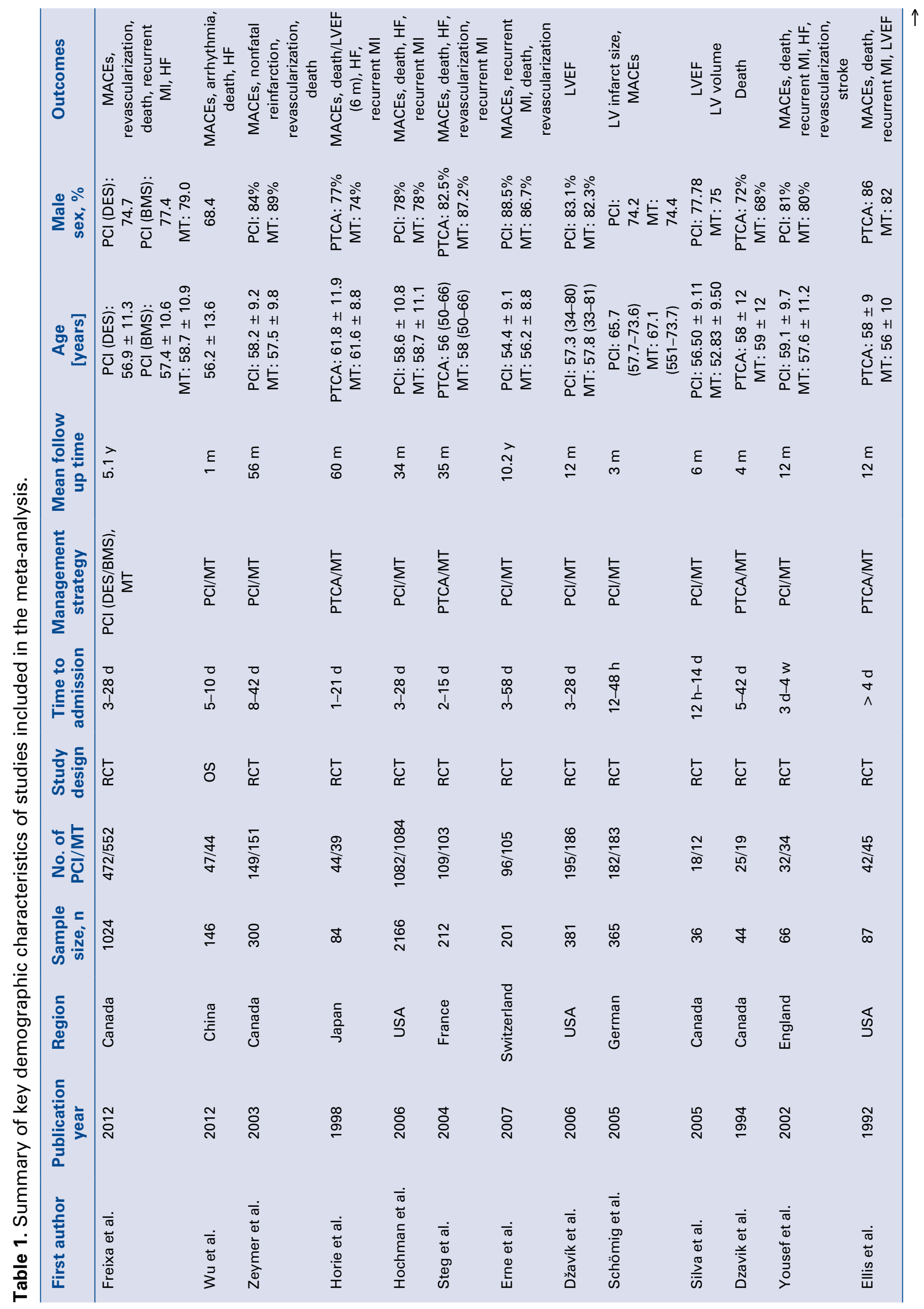




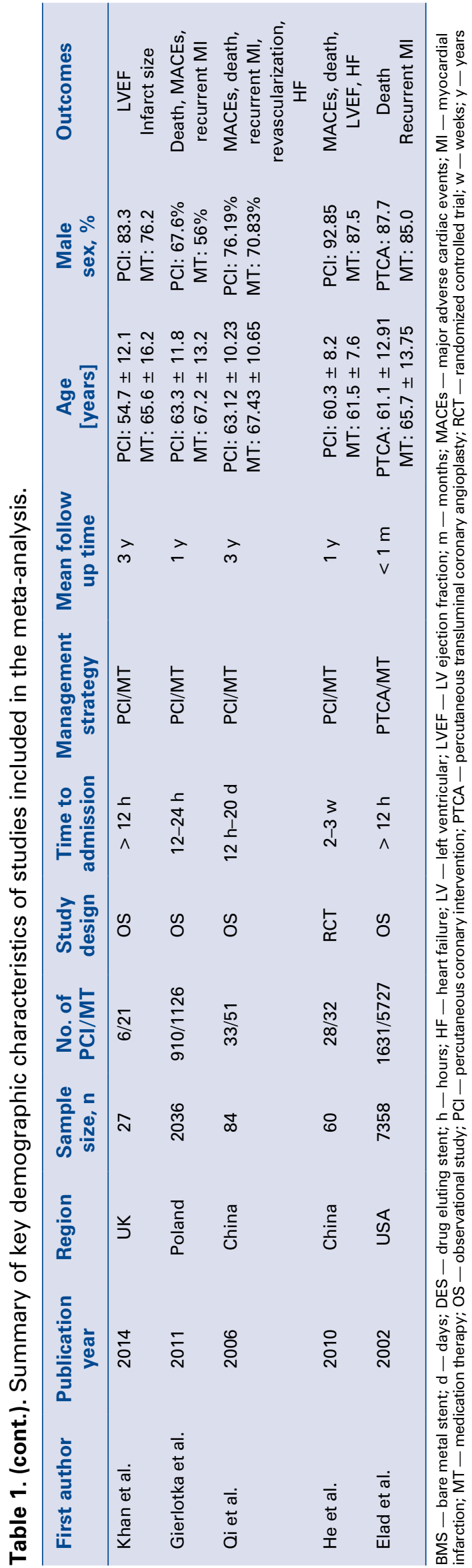

There was significant heterogeneity among studies included $\left(\mathrm{I}^{2}=55 \%, \mathrm{p}=0.009\right)$. The random-effects model was used to calculate the RR value. In total patients, relative to MT, late PCI was associated with decreased all-cause mortality (RR 0.62, 95\% CI $0.43-0.92 ; \mathrm{p}=0.02$, Fig. 2B). When stratified analysis according to time to PCI was performed, the heterogeneity disappeared in both the $>12 \mathrm{~h}$ $\operatorname{arm}\left(\mathrm{I}^{2}=0 \%\right)$ and the $2-60$ days $\operatorname{arm}\left(\mathrm{I}^{2}=20 \%\right)$. Subgroup analysis showed that decreased mortality was observed only in the $>12 \mathrm{~h}$ arm but not in the 2-60 days arm (Table 2).

\section{Recurrent MI}

There are 12 studies [8, 9, 11-17, 21, 23, 25] that reported the outcome of recurrent MI. Significant heterogeneity existed among the included studies $\left(\mathrm{I}^{2}=67 \%, \mathrm{p}=0.008\right)$. The random-effects model was used to calculate the $R R$ value. In all patients, there was a trend toward decreased recurrent MI (RR 0.70; 95\% CI 0.47-1.05; p = 0.08, Fig. 2C) in the late reperfusion group. When stratified analysis, according to time to PCI was performed, the heterogeneity disappeared in the $>12 \mathrm{~h}$ arm $\left(\mathrm{I}^{2}=0 \%\right)$ but remained in the 2-60 days arm $\left(\mathrm{I}^{2}=70 \%\right)$. Subgroup analysis showed late reperfusion with $>12 \mathrm{~h}$ was significantly associated with deceased recurrent MI (RR 0.53; 95\% CI $0.39-0.72, \mathrm{p}<0.001)$. However, no difference was found between late reperfusion with 2-60 days and MT in recurrent MI (RR 0.84, 95\% CI 0.46-1.51, $\mathrm{p}=0.55$, Table 2 ).

\section{Heart failure}

There are 8 studies $[8,9,11,13,14,16,23,24]$ that reported the outcome of HF. No significant heterogeneity existed among the studies included $\left(\mathrm{I}^{2}=40 \%, \mathrm{p}=0.11\right)$. The fixed-effects model was used to calculate the $R R$ value. The meta-analysis results showed that late reperfusion was associated with decreased incidence of $\mathrm{HF}$ rate (RR 0.76; 95\% CI $0.60-0.97 ; p=0.03$, Fig. 2D). Similarly, subgroup analysis showed late reperfusion PCI with $>12 \mathrm{~h}$ was significantly associated with decreased incidence of HF rate (RR 0.33 ; 95\% CI 0.15-0.70; $\mathrm{p}=0.004)$. However, a difference was not found between late reperfusion with 2-60 days and MT in HF (RR 0.85, 95\% CI 0.66-1.10; $\mathrm{p}=0.21$, Table 2).

\section{Sensitivity analysis}

A sensitivity analysis was conducted to examine the influence of each study on the pooled RRs. The pooled RRs showed no significant change when one study was deleted individually. Further 
Cardiology Journal 2019, Vol. 26, No. 4

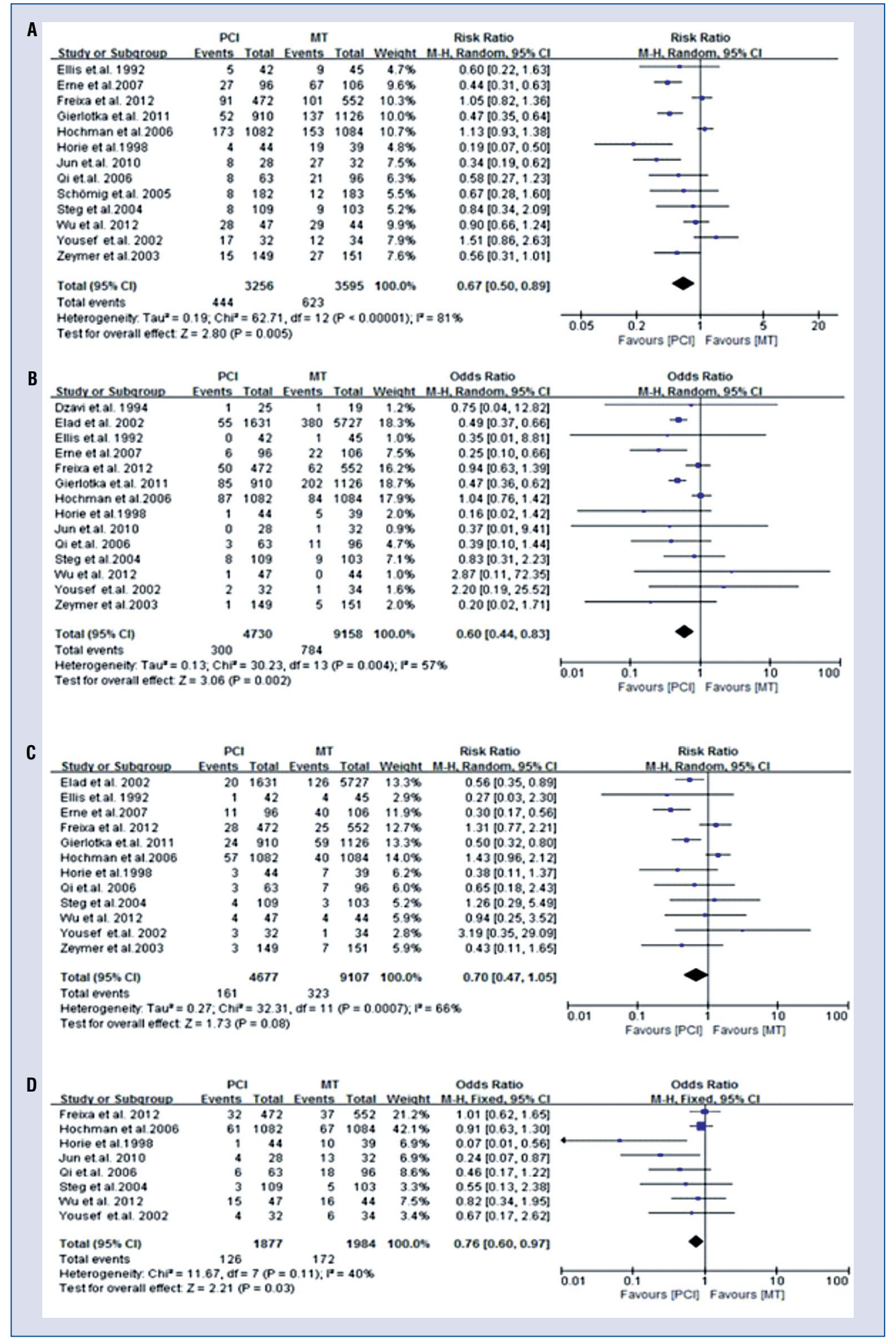

Figure 2. Forest plots of association of late percutaneous coronary intervention (PCI) versus medication therapy (MT) with clinical outcomes. A. major adverse cardiac events; B. All-cause mortality; C. Recurrent myocardial infarction; D. Heart failure; $\mathrm{Cl}$ - confidence interval. 
Table 2. Subgroup analysis according to time to percutaneous coronary intervention.

\begin{tabular}{|c|c|c|c|}
\hline Clinical outcomes & $I^{2}$ & RR (95\% CI) & $\mathbf{P}$ \\
\hline \multicolumn{4}{|l|}{ All-cause mortality: } \\
\hline Total & $57 \%$ & $0.60(0.44-0.83)$ & 0.002 \\
\hline$>12 \mathrm{~h}$ & $0 \%$ & $0.47(0.39-0.58)$ & $<0.001$ \\
\hline 2-60 days & $20 \%$ & $0.82(0.58-1.14)$ & 0.24 \\
\hline \multicolumn{4}{|c|}{ Major adverse cardiac events: } \\
\hline Total & $81 \%$ & $0.67(0.50-0.89)$ & $<0.001$ \\
\hline$>12 \mathrm{~h}$ & $30 \%$ & $0.46(0.36-0.60)$ & $<0.001$ \\
\hline $2-60$ days & $79 \%$ & $0.77(0.57-1.04)$ & 0.09 \\
\hline \multicolumn{4}{|c|}{ Recurrent myocardial infarction: } \\
\hline Total & $66 \%$ & $0.70(0.47-1.05)$ & 0.08 \\
\hline$>12 \mathrm{~h}$ & $0 \%$ & $0.53(0.39-0.72)$ & $<0.001$ \\
\hline 2-60 days & $70 \%$ & $0.84(0.46-1.51)$ & 0.55 \\
\hline \multicolumn{4}{|l|}{ Heart failure: } \\
\hline Total & $40 \%$ & $0.76(0.60-97)$ & 0.03 \\
\hline$>12 \mathrm{~h}$ & $61 \%$ & $0.33(0.15-0.70)$ & 0.004 \\
\hline 2-60 days & $0 \%$ & $0.85(0.66-1.10)$ & 0.21 \\
\hline
\end{tabular}

$\mathrm{Cl}$ - confidence interval; $\mathrm{RR}$ - relative risk

removed were the 4 observational studies in order to observe the stability of the results which also found no significant change in the pooled RRs, suggesting the results are stable and credible.

\section{Publication bias analysis}

In the present study, funnel plots were utilized to evaluate the publication bias of all included studies. No publication biases were found for this meta-analysis (Fig. 3).

\section{Discussion}

The present meta-analysis is based on the statistical pooling of 18 studies that enrolled a total of 14,677 patients, comparing late reperfusion with conservative MT in patients presenting more than $12 \mathrm{~h}$ after an AMI. Late PCI was reported (> $12 \mathrm{~h}$ ) after AMI was associated with decreased MACEs, all-cause mortality, recurrent MI and HF. However, late PCI within 2-60 days after AMI is not associated with improvements in clinical outcomes. This is the first meta-analysis to not only clarify the effect of late PCI versus MT on the prognosis of AMI patients but also to answer just how late is too late for PCI after AMI. Nevertheless, there are several points to be discussed when interpreting the results.

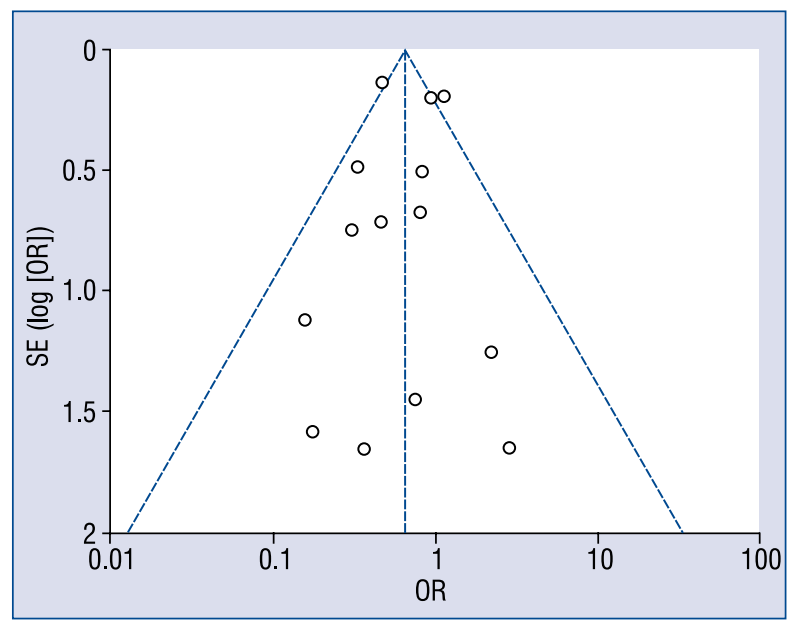

Figure 3. Funnel plot of test of publication bias; OR odds ratio; SE - standard error.

\section{Significant findings and clinical implications}

The findings that $>12 \mathrm{~h}$, but not $2-60$ days of late reperfusion had a beneficial effect on the clinical outcomes of AMI patients are potentially very significant. In the real world, more than $50 \%$ of patients undergo PCI during the subacute phase after an AMI [26-29]. Specifically, the current ACC/AHA guidelines for PCI suggests that 
late PCI is a class IIb (occluded artery) or class III (stenosis without evidence of spontaneous or provocable angina) indication [30]. However, the time point that is rational for PCI in the subacute phase of MI remains unclear. The present metaanalysis clarified this issue and suggested that late PCI should not be performed later than 2 days after the onset of symptoms.

\section{Pathophysiological mechanisms}

The pathophysiological mechanisms of late PCI are propitious to the prognosis of AMI and may be explained as follows: Firstly, opening of an IRA is beneficial to the salvaging of "hibernating" myocardium from death, even if late and beyond the time limit set for salvaging from myocardial necrosis [31]. Second, late reperfusion may favorably affect the apoptotic cascade, subsequently resulting in heart function protection [32]. In addition, opening of an IRA may interrupt the progression from hibernating myocardium to necrotic/apoptotic myocardium [33]. Busk et al. [34] observed the infarct size and myocardial salvage after primary angioplasty in patients presenting with symptoms for $<12 \mathrm{~h}$ vs. $12-72 \mathrm{~h}$ and supported that reducing time to treatment is pivotal because 'time is muscle'. However, Busk et al. [34] also demonstrated that substantial salvage was observed despite pain-to-balloon intervals of 12-72 h, even in patients with total occlusion of the IRA. Busk et al.'s [34] findings challenge the $12 \mathrm{~h}$ limit in primary angioplasty and suggest angioplasty of occluded IRAs should be performed within 48-72 h after AMI. Schömig et al. [18] also reported that primary angioplasty within $12-48 \mathrm{~h}$ reduced final infarct size and increased the salvage index when compared with MT. In the present data, clinical benefit was found from reperfusion with a $>12 \mathrm{~h}$ interval but not from a 2-60 day interval. The results are in line with the views of Busk et al. [34] and Schömig et al. [18].

\section{Validity and potential limitations of the meta-analysis}

This study has two advantages compared with Abbate et al.'s [8] meta-analysis published in 2008. The present study enrolled clinical trials that included a total of 14,677 AMI patients. Thus, results may be credible and stable. Identified patients received late PCI of $>12 \mathrm{~h}$ or 2-60 days, respectively and a concrete conclusion was made.

Several potential limitations are worth mentioning. First, in meta-analysis, many of the studies included had different entry criteria, study popula- tions, clinical outcomes, time to PCI, and follow-up time. This is a source of increased heterogeneity that may limit the generalizability of the conclusions to a broader AMI population. Therefore, a subgroup analysis was made and found heterogeneity disappeared or decreased. Second, there are 4 studies designed not as randomized trials, and therefore different study designs may influence results. Third, the participants in some studies including both PCI of within 12-48 $\mathrm{h}$ and within 2-60 days could not be divided into two groups to perform meta-analysis because of absence of stratification in the original studies. Thus, there is a proportion of 2-60 days PCI patients mixed in the $>12 \mathrm{~h}$ PCI subjects. Therefore, the results need to be verified by further rigorously designed large sample size clinical trials.

\section{Conclusions}

This meta-analysis of data from 18 studies shows beneficial outcomes in performing PCI late $(>12 \mathrm{~h})$ in the course of an AMI. However, PCI performed later than 2 days after onset of AMI may be unnecessary in clinical practice.

\section{Acknowledgements}

This work was supported by the National Natural Science Foundation of China (81560070).

Conflict of interest: None declared

\section{References}

1. Kawaji T, Shiomi H, Morimoto T, et al. CREDO-Kyoto AMI investigators. Long-term clinical outcomes in patients with ST-segment elevation acute myocardial infarction complicated by cardiogenic shock due to acute pump failure. Eur Heart J Acute Cardiovasc Care. 2016 [Epub ahead of print], doi: 10.1177/2048872616673535, indexed in Pubmed: 27708109.

2. Antman EM, Anbe DT, Armstrong PW, et al. ACC/AHA guidelines for the management of patients with ST-elevation myocardial infarction: a report of the American College of Cardiology/ American Heart Association Task Force on Practice Guidelines (Committee to Revise the 1999 Guidelines for the Management of Patients with Acute Myocardial Infarction). J Am Coll Cardiol. 2004; 44: e1-211.

3. Choi IkJ, Koh YS, Lim S, et al. Impact of Percutaneous Coronary Intervention for Chronic Total Occlusion in Non-Infarct-Related Arteries in Patients With Acute Myocardial Infarction (from the COREA-AMI Registry). Am J Cardiol. 2016; 117(7): 1039-1046, doi: 10.1016/j.amjcard.2015.12.049, indexed in Pubmed: 26993974.

4. Claessen BE, Dangas GD, Weisz G, et al. Prognostic impact of a chronic total occlusion in a non-infarct-related artery in patients with ST-segment elevation myocardial infarction: 3-year results from the HORIZONS-AMI trial. Eur Heart J. 2012; 
33(6): 768-775, doi: 10.1093/eurheartj/ehr471, indexed in Pubmed: 22240495

5. Welsh RC, Granger CB, Westerhout CM, et al. APEX AMI Investigators. Prior coronary artery bypass graft patients with ST-segment elevation myocardial infarction treated with primary percutaneous coronary intervention. JACC Cardiovasc Interv. 2010; 3(3): 343-351, doi: 10.1016/j.jcin.2009.12.008, indexed in Pubmed: 20298996.

6. Appleton DL, Abbate A, Biondi-Zoccai GGL. Late percutaneous coronary intervention for the totally occluded infarct-related artery: a meta-analysis of the effects on cardiac function and remodeling. Catheter Cardiovasc Interv. 2008; 71(6): 772-781, doi: 10.1002/ccd.21468, indexed in Pubmed: 18415952.

7. Abbate A, Biondi-Zoccai GGL, Appleton DL, et al. Survival and cardiac remodeling benefits in patients undergoing late percutaneous coronary intervention of the infarct-related artery: evidence from a meta-analysis of randomized controlled trials. J Am Coll Cardiol. 2008; 51(9): 956-964, doi: 10.1016/j. jacc.2007.11.062, indexed in Pubmed: 18308165.

8. Horie H, Takahashi M, Minai K, et al. Long-term beneficial effect of late reperfusion for acute anterior myocardial infarction with percutaneous transluminal coronary angioplasty. Circulation. 1998; 98(22): 2377-2382, indexed in Pubmed: 9832481.

9. Hochman JS, Lamas GA, Buller CE, et al. Occluded Artery Trial Investigators. Coronary intervention for persistent occlusion after myocardial infarction. N Engl J Med. 2006; 355(23): 2395-2407, doi: 10.1056/NEJMoa066139, indexed in Pubmed: 17105759.

10. Dzavík V, Buller CE, Lamas GA, et al. TOSCA-2 Investigators. Randomized trial of percutaneous coronary intervention for subacute infarct-related coronary artery occlusion to achieve long-term patency and improve ventricular function: the Total Occlusion Study of Canada (TOSCA)-2 trial. Circulation. 2006; 114(23): 2449-2457, doi: 10.1161/CIRCULATIONAHA.106.669432, indexed in Pubmed: 17105848.

11. Yousef ZR, Redwood SR, Bucknall CA, et al. Late intervention after anterior myocardial infarction: effects on left ventricular size, function, quality of life, and exercise tolerance: results of the Open Artery Trial (TOAT Study). J Am Coll Cardiol. 2002; 40(5): 869-876, indexed in Pubmed: 12225709.

12. Gierlotka M, Gasior M, Wilczek K, et al. Reperfusion by primary percutaneous coronary intervention in patients with ST-segment elevation myocardial infarction within 12 to 24 hours of the onset of symptoms (from a prospective national observational study [PL-ACS]). Am J Cardiol. 2011; 107(4): 501-508, doi: 10.1016/j. amjcard.2010.10.008, indexed in Pubmed: 21195380.

13. Freixa X, Džavík V, Forman SA, et al. Long-term outcomes after a strategy of percutaneous coronary intervention of the infarctrelated artery with drug-eluting stents or bare metal stents vs. medical therapy alone in the Occluded Artery Trial (OAT). Am Heart J. 2012; 163(6): 1011-1018, doi: 10.1016/j.ahj.2012.03.008, indexed in Pubmed: 22709754.

14. Wu Xl, Zhu R, Jiang H, et al. Different treatment interventions affect plasma NT-ProBNP levels and early exercise tolerance in patients with acute ST-segment elevation myocardial infarction. Postgrad Med. 2012; 124(2): 58-63, doi: 10.3810/ pgm.2012.03.2537, indexed in Pubmed: 22437216.

15. Zeymer U, Uebis R, Vogt A, et al. ALKK-Study Group. Randomized comparison of percutaneous transluminal coronary angioplasty and medical therapy in stable survivors of acute myocardial infarction with single vessel disease: a study of the
Arbeitsgemeinschaft Leitende Kardiologische Krankenhausärzte. Circulation. 2003; 108(11): 1324-1328, doi: 10.1161/01. CIR.0000087605.09362.0E, indexed in Pubmed: 12939210.

16. Steg PG, Thuaire C, Himbert D, et al. DECOPI Investigators. DECOPI (DEsobstruction COronaire en Post-Infarctus): a randomized multi-centre trial of occluded artery angioplasty after acute myocardial infarction. Eur Heart J. 2004; 25(24): 2187-2194, doi: 10.1016/j.ehj.2004.10.019, indexed in Pubmed: 15589635.

17. Erne P, Schoenenberger AW, Burckhardt D, et al. Effects of percutaneous coronary interventions in silent ischemia after myocardial infarction: the SWISSI II randomized controlled trial. JAMA. 2007; 297(18): 1985-1991, doi: 10.1001/jama.297.18.1985, indexed in Pubmed: 17488963.

18. Schömig A, Mehilli J, Antoniucci D, et al. Beyond 12 hours Reperfusion AlternatiVe Evaluation (BRAVE-2) Trial Investigators. Mechanical reperfusion in patients with acute myocardial infarction presenting more than 12 hours from symptom onset: a randomized controlled trial. JAMA. 2005; 293(23): 2865-2872, doi: 10.1001/jama.293.23.2865, indexed in Pubmed: 15956631.

19. Silva JC, Rochitte CE, Júnior JS, et al. Late coronary artery recanalization effects on left ventricular remodelling and contractility by magnetic resonance imaging. Eur Heart J. 2005; 26(1): 36-43, doi: 10.1093/eurheartj/ehi011, indexed in Pubmed: 15615797.

20. Dzavik V, Beanlands DS, Davies RF, et al. Effects of late percutaneous transluminal coronary angioplasty of an occluded infarctrelated coronary artery on left ventricular function in patients with a recent $(<6$ weeks) Q-wave acute myocardial infarction (Total Occlusion Post-Myocardial Infarction Intervention Study [TOMIIS]--a pilot study). Am J Cardiol. 1994; 73(12): 856-861, indexed in Pubmed: 8184807.

21. Ellis SG, Mooney MR, George BS, et al. Randomized trial of late elective angioplasty versus conservative management for patients with residual stenoses after thrombolytic treatment of myocardial infarction. Treatment of Post-Thrombolytic Stenoses (TOPS) Study Group. Circulation. 1992; 86(5): 1400-1406, indexed in Pubmed: 1423952.

22. Khan JN, Razvi N, Nazir SA, et al. Prevalence and extent of infarct and microvascular obstruction following different reperfusion therapies in ST-elevation myocardial infarction. J Cardiovasc Magn Reson. 2014; 16: 38, doi: 10.1186/1532-429X-16-38, indexed in Pubmed: 24884638.

23. Qi BQ, Yang XJ. Short-term and long-term therapeutics effects of varying treatment methods in patients with acute myocardial infarction: a comparison study. Suzhou University. 2006; 1 : 1.

24. He J, Ni J, Zheng JL, et al. Comparison of outcome in patients with non-ST-segment elevation myocardial infarction treated with selective percutaneous coronary intervention and drug respectively. Chongqi Yi Xue. 2010; 39: 2334-2337.

25. Elad Y, French WJ, Shavelle DM, et al. Primary angioplasty and selection bias inpatients presenting late $(>12 \mathrm{~h}$ ) after onset of chest pain and ST elevation myocardial infarction. J Am Coll Cardiol. 2002; 39(5): 826-833, indexed in Pubmed: 11869848.

26. Nishino S, Watanabe N, Kimura T, et al. The course of ischemic mitral regurgitation in acute myocardial infarction after primary percutaneous coronary intervention: from emergency room to long-term follow-up. Circ Cardiovasc Imaging. 2016; 9(8): e004841, doi: 10.1161/ CIRCIMAGING.116.004841, indexed in Pubmed: 27516478.

27. Brunetti ND, Correale M, Pellegrino PL, et al. Early inflammatory cytokine response: a direct comparison between spontaneous coronary plaque destabilization vs angioplasty induced. 
Atherosclerosis. 2014; 236(2): 456-460, doi: 10.1016/j.atherosclerosis.2014.07.037, indexed in Pubmed: 25173071.

28. Robbers LF, Delewi R, Nijveldt R, et al. Myocardial infarct heterogeneity assessment by late gadolinium enhancement cardiovascular magnetic resonance imaging shows predictive value for ventricular arrhythmia development after acute myocardial infarction. Eur Heart J Cardiovasc Imaging. 2013; 14(12): 1150-1158, doi: 10.1093/ehjci/jet111, indexed in Pubmed: 23764484.

29. Dangas GD, Claessen BE, Mehran R, et al. Clinical outcomes following stent thrombosis occurring in-hospital versus out-ofhospital: results from the HORIZONS-AMI (Harmonizing Outcomes with Revascularization and Stents in Acute Myocardial Infarction) trial. J Am Coll Cardiol. 2012; 59(20): 1752-1759, doi: 10.1016/j.jacc.2011.12.042, indexed in Pubmed: 22575312.

30. Levine GN, Bates ER, Blankenship JC, et al. 2015 ACC/AHA/ /SCAI Focused Update on Primary Percutaneous Coronary Intervention for Patients With ST-Elevation Myocardial Infarction: An Update of the 2011 ACCF/AHA/SCAI Guideline for Percutaneous Coronary Intervention and the 2013 ACCF/AHA Guideline for the Management of ST-Elevation Myocardial Infarc- tion. J Am Coll Cardiol. 2016; 67(10): 1235-1250, doi: 10.1016/j. jacc.2015.10.005, indexed in Pubmed: 26498666.

31. Abbate A, Bussani R, Biondi-Zoccai GGL, et al. Persistent infarct-related artery occlusion is associated with an increased myocardial apoptosis at postmortem examination in humans late after an acute myocardial infarction. Circulation. 2002; 106(9): 1051-1054, indexed in Pubmed: 12196327.

32. Abbate A, Bussani R, Biondi-Zoccai GGL, et al. Infarct-related artery occlusion, tissue markers of ischaemia, and increased apoptosis in the peri-infarct viable myocardium. Eur Heart J. 2005; 26(19): 2039-2045, doi: 10.1093/eurheartj/ehi419, indexed in Pubmed: 16030061.

33. Sabia PJ, Powers ER, Ragosta M, et al. An association between collateral blood flow and myocardial viability in patients with recent myocardial infarction. N Engl J Med. 1992; 327(26): 1825-1831, doi: 10.1056/NEJM199212243272601, indexed in Pubmed: 1448120.

34. Busk M, Kaltoft A, Nielsen SS, et al. Infarct size and myocardial salvage after primary angioplasty in patients presenting with symptoms for $<12$ h vs. $12-72$ h. Eur Heart J. 2009; 30(11): 1322-1330, doi: 10.1093/eurheartj/ehp113, indexed in Pubmed: 19357105. 